\title{
Developing Awareness of Questioning Strategies for Second Language Learner Teachers
}

\author{
Saihua Xia \\ Murray State University, USA
}

\begin{abstract}
Asking varying levels of questions within the cognitive domain is not an innate skill, which is especially true with English as a second language learner teachers. To develop their awareness of teacher questioning strategies, an eight-week quasi-experimental study, designed based on the Revised Bloom's Taxonomy (Anderson \& Krathwohl, 2001) has explicitly taught participants $(N=14)$ questioning strategies of asking varying levels of questions and Divergent Questions through intense restructuring activities and a Question-Question Game. Pre-and post-tests, and pre-and post-questionnaires, including question journals, are administered. The results, compared with the control group $(N=7)$ using paired-samples $t$ tests show that explicit instruction has developed participants' awareness of formulating levels and varieties of questions. Participants have significantly $(t(13)=3.67, p<.05)$ asked more higher order questions such as Analysis Questions. They have also significantly $(t(13)=-2.85, p<.05)$ reduced lower order questions such as Understand Questions resulting from the promoted awareness of their existing strategies. Analysis of the qualitative data provides supporting evidence, further indicating specific questioning levels and cognitive processes for which L2 learner teachers lack awareness. This study is the first one that has experimentally taught L2 teacher questioning through the Revised Taxonomy and opens new directions for teacher training.
\end{abstract}

Index Terms - questioning strategies, levels of questions, awareness, L2 learner teachers, explicit instruction, quasi-experimental, teacher questioning development

\section{INTRODUCTION}

Asking varying levels of questions within the cognitive domain is not an innate skill, even if you grew up in a Socratic educational context. This view is first agreed by Nappi's argument emphasizing the planning of questions (2017, p.38), "developing questions that are scaffolded ---beginning with recall and working up to analysis, synthesis, and creation - requires careful planning" when she studied questioning in developing critical thinking skills. The view is also supported by the emphasis of "designing questions" (p. 179) in Sun's study (2012) on the relationship between teacher questioning and student learning. The view is especially true with English as a second language (L2) pre-service teachers called learner teachers in this study. A majority of them come from non-Socratic educational contexts in which they are trained to ask questions in classrooms. Instead, they are praised to be silent and obedient to teacher authority. This lack of questioning instruction is documented in the classroom "silence" or "reticence" studies where their participation behaviors are questioned (Jackson, 2002; Xia, 2009). It is further evidenced in the zero training finding from the pre-questionnaire of this study and in the current call for training teacher questioning behaviors (Davoudi \& Sadeghi, 2015; Dös et al, 2016).

Questioning is such a fundamental scaffolding strategy in teaching that shapes language learning and teaching paths. Teacher instruction cannot proceed without teacher questioning as Celce-Murcia, Brinton and Snow (2014) stated "70\% of class time consists of the teacher talking or asking questions" (p. 345). In the past decades, the problem of questioning has invited rich empirical investigation into types of teacher questions (Brock, 1986; Cotton, 1988; Döş et al, 2016; Nunan, 1990), functions of questions in various discourses (Freed \& Ehrlich, 2010; Koshik; 2010), and functions of teacher questions (Döş et al, 2016; McCormick \& Donato, 2000; Yaqubi \& Mozaffari, 2011) in L2 language classrooms. It has also examined the relationship of L2 teacher questioning and student learning (Sun, 2012; Toni \& Parse, 2013; Wu, 1993) including teacher beliefs (Farrell \& Mom, 2015). These studies have collected teacher questions and conducted systematic content analysis to reveal the scaffolding functions of questions in contexts. However, limited research has directly investigated the development of L2 teacher questioning, a fundamental component of the teacher strategic competence (Canale \& Swain, 1980). Relevant interventional research to develop L2 teachers' awareness of questioning strategy seems missing from the current literature, though Brown and Lee (2015) strongly advocated, "teachers need to develop a repertoire of questioning strategies for the purpose of initiating and sustaining interaction" (p. 262). In addition, the ongoing call for contextualizing L2 learning and teaching (LarsenFreeman, 2018; Ortega, 2009), including teacher questioning behaviors (Davoudi \& Sadeghi, 2015; Dös et al, 2016), recreates research currency and focus that this study intends to investigate.

The present study investigates the problem from the focus of developing L2 advanced learner teachers' awareness of forming varying levels of questions according to the Revised Bloom's Taxonomy (Anderson \& Krathwohl, 2001) and constructing Divergent Questions through applying planned and intensified restructuring activities. The study design is informed by the social-cognitive perspective of strategy learning (Cohen, 2010; Cohen \& Macaro, 2007; O’Malley \& 
Chamot, 1990; Oxford, 1990, 2011, 2017). It attempts to develop learner teachers' awareness of questioning strategies through explicit instruction, engaging interactions, and contextualized restructuring and productive activities (DeKeyser, 1997, 2007; Ellis, 2002; Mackey, 2006, 2008; Ortega, 2009; Schmidt, 1990, 1995). Specifically, it operationalizes the framework of the Revised Bloom's Taxonomy (Anderson \& Krathwohl, 2001, pp. 67-68; shortened for Revised Taxonomy) to develop questioning strategies at six levels: Remember, Understand, Apply, Analyze, Evaluate, and Create. In the study, the participants are called learner teachers because English is their L2 and they concurrently develop L2 competence in the English context while learning to become effective teachers, which further justifies why the study is simultaneously situated in learner strategic competence development and teacher education.

\section{RESEARCH ON QUESTIONING STRATEGIES}

Research on L2 learner strategy development has substantially investigated learner "strategic investment" (Brown \& Lee, 2015, p.51) in acquiring a range of language skills such as learning grammar explicitly, contextualizing vocabulary learning, and monitoring speaking (Cohen \& Macaro, 2007). This line of research was mainly inspired by the descriptive studies conducted by O'Malley and Chamot, and other researchers' seminar work between mid 1980s to 1990s. They became more accepted due to Oxford's pioneering work on learning strategies driven by "the Strategy Inventory for Language Learning (SILL)” (1990, p. 209). Later, Ortega (2009, p. 210) critically reviewed these directional studies and questioned contextualization while studying the value of L2 learning strategies to differentiate success. She argued "L2 learning strategic behaviors cannot and should not be reduced to a taxonomy of observed heuristics and self-reported mental processes" (p. 211). To address Ortega's criticism about contextualization, this study starts from considering learner teachers' prior L2 curricular context in which they received limited explicit questioning instruction. It continues to explicitly instruct questioning strategies facilitated by content they know to contextualize the learning process, empowering them with scaled and targeted scaffolding competence.

By the middle of the $20^{\text {th }}$ century, a substantial body of educational research on children questioning had been conducted in the interventional form within the first language (L1) English context. They examined receiving questioning training (Blank \& Covington, 1965), praising and modeling questioning (Zimmerman \& Pike, 1972), and raising children's awareness of categories in the Twenty Questions games (Nelson \& Earl, 1973). Later in 1999, Lindfors investigated children's questioning by analyzing children's dialogues with partners to see how the inquiry act was used to make sense of the world. She emphasized "languaging" (p. 3) that united questioning forms (structures) and functions (purposes) in texts. Her research initiated subsequent keen interest in studying functions of questioning in real contexts. By 1990s, this body of research had contributed empirical understanding to children questioning development in L1 contexts, but not regarding L2 contexts nor adult questioning. While questioning education appears as such a "done deal" in the L1 English context, this is not the case within non-English contexts, especially when L2 learner teachers do not grow up with a Socratic education as it has teachers like Lindfors who had taught 20 years of "children questioning” by 1999 ( p. 81). They receive limited training in questioning during prior education. More importantly, adults, as Grenfell and Macaro (2007) argued, learn things differently than children because they think more analytically about "the process of language learning" (p. 9) and are "often the subjects of empirical studies on strategy instruction" (p. 15). They desire explicit instruction on forms and structures of questioning to catch up on the education they have missed.

In 2008, McDonough and Mackey realized the needs of questioning form development in adults and investigated 46 Thai English as a Foreign Language (EFL) undergraduates' development of question formation through syntactic priming and communicative activities (p.31). The activities were performed by trained and more advanced L2 English interlocutors scripted with developmentally advanced question forms. The participants completed pre-and post-tests and carried out communicative activities with the scripted interlocutors. The researchers' contributing finding to understand questioning development was that "productively using a [questioning] form in one's own way could be more beneficial for development than simply repeating or mimicking that form" (p. 43), which was consistent with the results identified by other similar research (Mackey, 1999; McDonough \& Mackey, 2006). However, the research has not investigated learner teachers who need the development substantially.

In 2010, two researchers focused on examining functions that utterances can exercise in institutional discourse. Sarangi examined activity types that determine what kinds of utterances function as questions and found that backchannels as "pseudo-questions" in the context of genetic counseling sessions were nondirective. Koshik analyzed questioning in one-on-one L2 college writing conferences and identified "designedly incomplete utterance" was one form of questioning used by teachers to target students' errors (p.164). Their findings indicate that contexts, interacting with institutional discourses, could shape the structure of questioning, which further supports the assumption of the present study that academic instructional discourse is structured based on certain fundamental levels of questioning. The varying cognitive levels and processes defined by the Revised Taxonomy could be part of the structure because teachers and students persistently and interactively investigate levels of knowledge and problems within the structure in academic discourses.

The next body of research examined the relationship between teacher questions and learner attitudes including learning. In 1993, Wu studied teacher questions collected from ESL teachers in secondary schools in Hong Kong (HK) through recordings. He examined the relationships among question types, questioning strategies, student attitudes and 
interaction patterns. He found display questions were more effective while referential questions did not elicit longer nor more complex responses in the HK context. Wu's finding seems consistent with Cotton's (1988) finding that lower order questions (display questions) are more effective than higher order questions (referential questions) in eliciting responses, but it contradicts Brock (1986) and Nunan (1990) who concluded in their earlier teacher questioning studies that referential questions elicit more interactive responses. This type of inconsistency obtained from the last century's research invites new investigation in today's context to fill the void of questioning training in L2 learner teachers.

In 2012, Sun conducted a survey study on the teacher-student relationship affected by the use of teacher questions in an EFL college context. After analyzing the data collected from 73 participants regarding strategies and relationships, she found that students preferred teachers to use various strategies to make them feel relaxed, give them more wait time, and establish a more respectful relationship. Sun noticed that teachers surveyed lacked specific questioning strategies. She called for designing classroom questions aiming at cognitive engagement and sensitivity to student-teacher relationship. Sun's call was legitimate; however, she did not realize that designing purposeful academic questions needed training and explicit instruction. If teachers were not made aware of varying cognitive levels of questioning that could empower them to create new student-teacher relationship, it would be hard for them to change their current questioning behaviors.

Most recently, Döş et al (2016) investigated 170 primary school teachers' questioning strategies through questionnaires and content analysis in an EFL context. They looked at teacher question functions and the association between teacher questions (Qs) and cognitive levels of the Bloom's Taxonomy. Findings showed 67\% of the Qs reported were Divergent Qs while 33\% of them were convergent Qs. Regarding levels of Qs, teachers reported using $21.1 \%$ of application Qs, $19.9 \%$ evaluation Qs, $18.1 \%$ of analysis Qs and, 16.5\% of remember Qs. These numbers seem to indicate that teachers asked more higher order Qs than lower order Qs. However, a closer analysis found a mismatch between teacher self-reported questioning levels and the current research on questioning levels according to the researchers. They concluded that the participating teachers had "misconceptions about convergent and divergent question types" (p. 2074) and strongly called for "studies on the teaching of questioning strategies" (p. 2076), providing training to both pre-and in-service teachers, and even as a subject (p. 2077). This emphasis resonates the exact same call for "in-service programs to help teachers strengthen their classroom questioning behaviors"(p. 86) made by Davoudi and Sadegh (2015) after reviewing 60 experimental studies of classroom questions over the last three decades.

Overall, this review finds that the problem of questioning strategy development is well researched in L1 child questioning, teacher questioning and functions, and the relationship between teacher questioning and learning. However, the review finds that explicit questioning strategy training in pre- and in-service L2 teacher training programs is lacking. Interventional studies on developing L2 teacher questioning are even fewer. Teachers' misconceptions about levels and types of Qs exist. The needs of contextualizing L2 learner teachers' training to catch up on the questioning education they have missed in their prior non-Socratic education is demanded. Therefore, this quasi-experimental study is conducted to address the problem. The Revised Taxonomy is operationalized to develop L2 learner teachers' awareness of questioning strategy in formulating varying levels of Qs and making Divergent Questions for specific scaffolding purposes in classrooms. In this study, Divergent Questions (shortened for DQs) are defined as asking questions from new perspectives based on the same content focus (McKenzie, 2005; Morgan \& Saxton, 1991). Questioning strategy focuses on developing awareness of perspectives, levels, and divergence of asking Qs. It is specifically defined as a conscious effort made to formulate varying levels of cognitive interrogations and to plan divergent interrogations supported by intentionally selected structures and cognitive processes to productively interact with the complexity of the content under investigation in academic contexts. This definition is adapted from Freed and Ehrlich (2010, p. 6) and inspired by the Revised Taxonomy. Thus, these two research questions are developed:

1. To what extent can explicit questioning strategy instruction develop learner teachers' awareness of strategies to formulate levels of questions?

2. To what extent can explicit questioning strategy instruction raise learner teachers' awareness of strategies to develop divergent questions?

\section{METHODOLOGY}

\section{A. Participants}

Two groups of volunteer students participated in this eight-week quasi-experimental study. The experimental group (EXG) consisted of 14 L2 TESOL learner teachers. They had an advanced level of language proficiency due to a BA in EFL with an IELTs score of 6.5 or above reported in the pre-questionnaire, and their enrollment in an MA TESOL program at a midwestern American university from one to three semesters. They were nine females and five males with an average age of 26.5 years old from China, Korea, Saudi Arabia, and Taiwan. The control group (CG) included seven participants from similar backgrounds enrolled in the same program. They were four females and three males with an average age of 25.4 years old from China, Iran, Saudi Arabia, and Vietnam.

\section{B. Instruments}

Pre-Test and Post-Test 
Pre-and post-tests to elicit participants' awareness of questioning strategies were designed by the researcher and respectively administered before and after the eight-week training. Two intermediate articles were selected from the book called Language Myths (Bauer \& Trudgill, 1998) as readings in the tests using the criteria of relevance to the topic of language that participants knew, complexity of writing aligned with participants' language proficiency, and purpose of asking Qs about content in this study. Each article was seven pages long and approximately 450 words per page. In the pre-test, each participant received a copy of the first article to read as much time as possible for understanding and then received 10 minutes to ask as many Qs as possible. Flexible reading time was given to ensure a maximum understanding of the content in the readings so that they can ask Qs showing optimal ability of questioning in the measurable 10 minutes' time. All participants gathered in a computer lab and each was assigned a computer before reading. They typed in Qs and emailed the Qs to the researcher immediately after finishing. All of these procedures were repeated exactly for the post-test except the participants received the second article.

Pre-Questionnaire and Post-Questionnaire

A two-section questionnaire, called "pre-questionnaire" and designed by the researcher was given before the treatment to collect participants' demographics and English educational experience of receiving explicit instruction in questioning.

Another 11-item questionnaire, called "post-questionnaire" (Appendix A) and designed by the researcher was given during the $9^{\text {th }}$ week to elicit participants' retrospective awareness of questioning strategies learning after the training. Qs1, 9, 11, elicited participants' holistic reflection upon the training regarding the degree of awareness. Qs 2 and 3, multiple choice Qs, elicited the extent of awareness to ask different Qs through a Likert Scale of five descriptors: fullest, noticeable, some, little, not sure. To verify the responses given in Qs 2 and 3, Qs 4, 5, 8, 10 continued to elicit responses and examples to illustrate them. Q6 checked practices that did not contribute to the awareness to cancel the errors that students may have made when responding Qs 2 and 3. Q7 asked about participants' outside application experience during the treatment weeks.

\section{Treatments}

The 14 EXG participants received six levels of questioning strategy training provided by the researcher based on the Revised Taxonomy (Appendix B) in eight treatment sessions weekly after regular classes in one fall semester. The first session focused on the two levels of questioning "Remember" and "Understand," and the next four were distributed evenly across the remaining four levels of questioning, "Apply, Analyze, Evaluate, and Create". The subsequent two sessions worked on DQs. The last session, including partial efforts of the last two, practiced holistically on stating Qs clearly, accurately, and meaningfully. A Thinking Skills Handout (Appendix C) was provided in each session to facilitate posing and restructuring Qs. The handouts were created based on thinking skills (processes) illustrating each aligned level of cognitive dimension (levels) in the Revised Taxonomy (Appendix B), questioning functions/structures (McKenzie, 2005; Morgan \& Saxton, 1991), and Wiederhold's Question Matrix (2007). The central practices throughout the sessions were revising pre-test Qs returned, associating Qs to levels of Qs under training, and questioning divergently through a Question/Question Game (Q-Q Game) (Morgan \& Saxton, 1991). This Game is a group activity to practice questioning based on a source $Q$. It requires participants to answer a $Q$ with a $Q$ that offers a clear and meaningful response to the source $Q$ as well as opens up a new perspective to answer the source $Q$ (Appendix D). The participants practiced in pairs and each asked a minimal of four-five turns in each practice. In the $9^{\text {th }}$ week, they took the post-test in the lab and completed the post-questionnaire.

Each session lasted 60-75 minutes. The first 25 minutes were used to instruct participants on the selected level of questioning, to align thinking skills and functions with Qs, and to engage participants in analyzing returned Qs. For example, at the level of "Understand," participants were instructed on thinking skills (e.g. interpreting, exemplifying) using the illustrative examples of the level from the Revised Taxonomy. Relevant questioning functions (e.g. Can you rephrase?) were provided in the handout to facilitate instruction and practices. The next 30 minutes were used for asking levels of Qs and DQs through the Q-Q Game. In the last 15-20 minutes, participants worked in pairs revising each other's Qs utilizing the criteria of clarity, accuracy, and meaningfulness; finally submitting revised questions to the researcher.

\section{Data Collection}

This study triangulated multiple sources of quantitative and qualitative data during the treatment process to catch the complex nature of the problem and reduce the limitation of the number of participants in the study. Table 1 provides the data sources:

TABLE 1

DATA SOURCES

\begin{tabular}{ll}
\hline Source & Description of the Source \\
\hline 1 & Pre- \& post-tests \\
2 & Pre- \& post-questionnaires \\
3 & Samples of questioning practices \& notes from treatment sessions \\
4 & Question journals \\
5 & Pre-\& post-tests by the CG \\
\hline
\end{tabular}


Pre- and post-tests, pre-and post-questionnaires were the primary sources of data. Samples of questioning practices throughout the sessions were also collected in the form of written notes and revised Qs. For the purpose of verifying questioning awareness in new contexts, the 14 EXG participants were asked to keep biweekly journals to record Qs they initiated inside regular semester classes. Simultaneously, the CG participants took the pre-and post-tests, but they did not receive treatment information nor weekly treatment practices.

\section{ANALYSIS}

To identify answers to the research questions (RQs), both quantitative and qualitative analyses were conducted. First the Qs collected from the two tests were coded by two independent coders according to the six levels of questioning and the aligned 19 cognitive processes (Appendix B) illustrated in the Revised Taxonomy. Of the six levels, Remember, Understand, and Apply Qs were further coded as Lower Order Questions (LOQs) while Analyze, Evaluate, and Create were coded as Higher Order Questions (HOQs). The interrater Pearson Correlation $(r=0.83)$ was significant ${ }^{1}$. Next, a descriptive analysis using the SPSS 25 statistical program was conducted to identify the difference between LOQs and HOQs. Paired-samples $t$ tests were used to determine whether the mean differences between the pre-test and the posttest of the paired observations were significantly different (Cronk, 2018). Furthermore, a qualitative analysis was conducted to identify participants' tendency of asking a particular level of Qs, including distinct cognitive processes through comparing the types of Qs asked in both tests. An additional analysis of the responses collected from the postquestionnaire was performed to show the extent of awareness of questioning strategy regarding the two RQs. Finally the results were compared between the EXG and the CG to assess the significance.

\section{RESUlTS}

To answer RQ1, a descriptive statistical analysis of three paired samples: LOQs vs. LOQs, HOQs vs. HOQs, and total pre-test Qs vs. total post-test Qs asked by the participants $(N=14)$ in both tests were conducted. The analysis shows that the mean of LOQs in the pre-test $(M=4.64, s d .2 .47)$ was different than that $(M=2.43, s d=1.45)$ in the post-test while the mean of HOQs $(M=3.00, s d=1.88)$ in the post-test was also different than that $(M=1.64, s d=1.15)$ in the pre-test. In other words, participants asked more LOQs in the pre-test while they asked more HOQs in the posttest. However, the total number of Qs was fewer in the post-test when compared with that in the pre-test $(M=6.29, s d=$ 2.87 vs. $M=5.43, s d=2.24)$. To measure the significance of these mean differences, three paired-samples two-tailed $t$ tests $(p \leq .05)$ were conducted and Table 2 shows the results:

TABLE 2

PAIRED SAMPLE T TESTS IN PRE-AND POST-TESTS

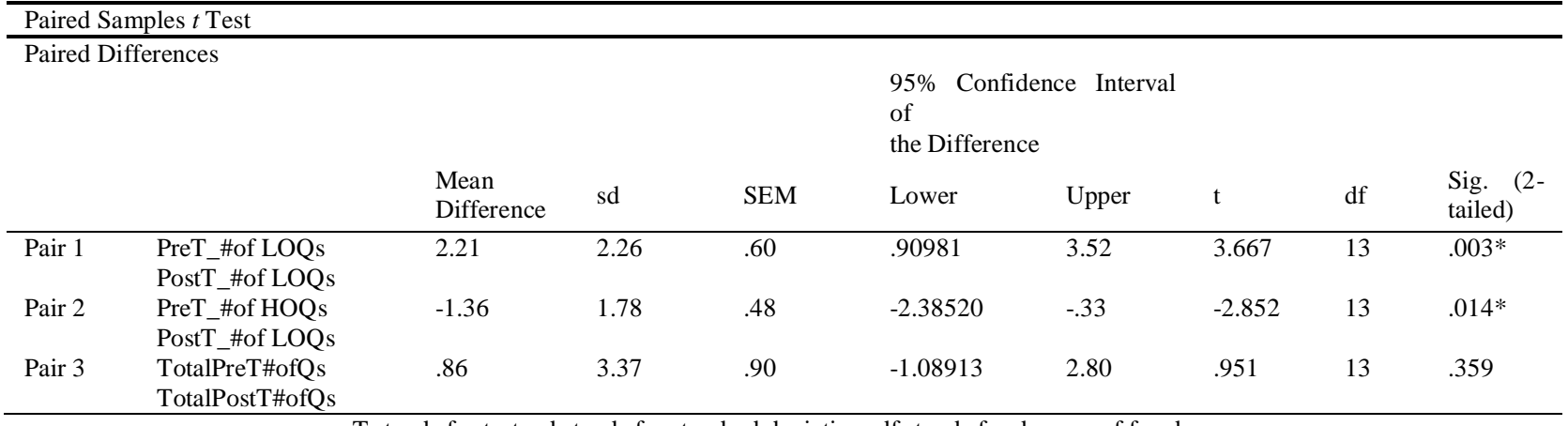

T stands for test; sd stands for standard deviation; df stands for degrees of freedom

The first $t$ test compared the mean number of LOQs $(M=4.64, s d$. 2.47) in the pre-test to that in the post-test $(M=$ $2.43(s d=1.45)$. A significant decrease of the number of LOQs was found $(t(13)=3.67, p<.05)$. The next $t$ test compared the mean number of HOQs in the pre-test $(M=1.64 ; s d=1.15)$ with that in the post-test $(M=3.00 ; s d=1.88)$. A significant difference was also found $(t(13)=-2.85, p<.05)$. The final $t$ test tested the total mean number of Qs asked in the pre-test $(M=6.29 ; s d=2.87)$ against that of the post-test $(M=5.43(s d=2.24)$. This test failed to reject the null hypothesis $(t(13)=.359, p>.05)$.

Another descriptive analysis conducted to see the differences between each level of Qs asked showed that Understand Qs took 52\% of the total number of Qs asked in the pre-test while Analysis Qs increased from $10 \%$ in the

\footnotetext{
${ }^{1}$ Two independent coders (the researcher \& a trained research assistant) first discussed sample Qs through examining level-by-level, process-byprocess definitions and illustrative examples, and then practiced coding together. After that, each coded two sets of randomly selected Qs independently (Interrater Correlation $r=0.83$ ). Specifically, they coded each question first as a "Level Q" and then as a "Process Q" based on the aligned cognitive process specified under the designated level and finally as a "LOQ" or "HOQ". For example, this question, "How can we make learning second language easy?" was coded as an Implementing (process) Q under the Apply level because it tried to put thoughts into action by using procedures to unfamiliar tasks and it was a LOQ. Lastly, questioning functions (e.g. What would happen if ...?) relevant to the level of Apply shown in Thinking Skills Handouts were referenced to support the coding.
} 
pre-test to $53 \%$ in the post-test and Understand Qs reduced from 52\% to $18 \%$. When comparing the two groups, one interesting finding was that the EXG asked a similar percentage (23.8\% vs. 27.6\%) of Yes/No Qs in both tests while the CG increased $27.1 \%$ of Yes/No Qs in their post-test from 33\% to $60.1 \%$, and their Qs were rarely supported by a variety of questioning functions. One surprise was that both groups asked the least number of Creation Qs when comparing both tests. The analysis of the post-questionnaire showed that $93 \%$ of the participants reported a positive/very experience with the questioning training. 79\% of them reported asking levels of Qs (Table 3).

To answer RQ2, Table 3 summarizes the descriptive analysis results reflecting the extent of awareness of DQs and levels of Qs reported in the post-questionnaire. Awareness is expressed in Aspects, Percentages (\%) and Examples.

TABLE 3

REPORTED AWARENESS FROM RESPONSES TO THE POST-QUESTIONNAIRE

\begin{tabular}{|c|c|c|}
\hline Awareness Aspects & $\%$ & Examples to Show Extent of Awareness \\
\hline Positive Experience & $93 \%$ & Positive experience \\
\hline Asking Levels of Qs & $79 \%$ & Noticeable extent \\
\hline Asking Different Qs & $86 \%$ & $\begin{array}{l}\text { Noticeable extent: "I gradually understand how to ask questions more } \\
\text { effectively and what's more kinds of questions we can think about from the } \\
\text { source question." }\end{array}$ \\
\hline Q-Q Game & $57 \%$ & $\begin{array}{l}\text { Stimulate minds to produce types of/different Qs; get different views of the } \\
\text { same Qs }\end{array}$ \\
\hline First-Time Noticing Questioning Strategies & $100 \%$ & $\begin{array}{l}\text { Each Q belongs to a different category/process; group Q-Q game; "I didn't } \\
\text { notice that I always ask simple questions." }\end{array}$ \\
\hline Applying questioning strategies & $79 \%$ & $\begin{array}{l}\text { Q formation functions; "ask open Qs to get answers that are not simple yes or } \\
\text { no"; "ask Qs from different perspectives in my Cultural Class" }\end{array}$ \\
\hline
\end{tabular}

$\mathrm{Q}$ stands for question; \% refers to the percentage of participants aware of the aspects in the left column.

Table 3 shows $86 \%$ of participants asked different and DQs. This finding was consistent with the evidence that $57 \%$ of the participants actually asked DQs in their post-test when the researcher examined the types of Qs, including the aligned 19 cognitive processes to see divergence and perspectives. All participants responded that this was the first time for them to notice questioning strategies such as asking different categories of Qs and proposing Qs from different perspectives. Seventy-nine percent $(79 \%)$ of the participants reported that they tried to apply the strategies in new situations. Examining the percentages further, the Q-Q Game appeared to be a welcome training tool for opening up new perspectives to ask DQs because $57 \%$ of the participants noticed the effects of this game while exploring DQs.

One integrated strategy that participants practiced in the training was stating Qs clearly, accurately, and meaningfully, which meant to deepen the extent of awareness of questioning strategy. An analysis of the length and clarity of the Qs asked in both tests found the results in Table 4.

TABLE 4

LENGTH \& CLARITY OF QS

\begin{tabular}{lll}
\hline & Pre-Test & Post-Test \\
\hline \# of Words Per Q. & $21.4(M)$ & $17(M)$ \\
Q Patterns Emerged & Embedded Qs & Variety: apply native-like Q functions \\
& Ungrammatical Qs & Length: shorter \\
& Incomplete Qs & Clarity: structured, meaningful/relevant \\
\hline
\end{tabular}

Q stands for question; $M$ stands for mean

Table 4 shows the mean length per Q changed from 21.4 words in the pre-test to 17 words in the post-test. A further comparison of the Qs revealed the emergence of different questioning patterns such as using more native-like structures/functions, shortening Qs with noticeable efforts, and considering precise use of structures and Q meaning. This type of evidence was also consistently identified in the question journals. For example, Student (S) 8 , during the $7^{\text {th }}$ week of the training, asked in the Language Testing class that she was taking during the semester: "What is the difference between the median and mean" and categorized it as a comparing Q. In Treatment 2, S4 asked, "Is language have [sic] directly related to culture?" but during the $8^{\text {th }}$ week of training asked: "What makes a good teaching blog?"

Comparing With the Control Group (CG)

A descriptive analysis of the Qs asked by the CG in the pre- and post-tests was conducted. The CG asked a majority of Understand Qs (68\% in pre-test vs. 72\% in post-test) in both tests. When examining the Understand Qs more closely, $25 \%$ in the pre-test vs. $33 \%$ in the post-test were found to explore the level of Understanding through using the cognitive process of Comparing. To identify the significance of the mean differences of asking levels of Qs between the two groups, a paired-samples $t$ test was conducted and it did not reject the null hypothesis $(p=.338>.05)$. However, an interesting finding was that $60.1 \%$ of the Qs asked by the CG in the post-test were Yes/No Qs, which closely matched the $68 \%$ of the type of Understand Qs in the same test. In contrast, 27.6\% of the Qs asked by the EXG in the post-test were Yes/No Qs.

\section{DISCUSSION}


To identify the extent that explicit instruction on questioning strategies develop participants' awareness of asking levels of Qs and DQs, this study is conducted. A descriptive statistical analysis through three paired-samples $t$ tests of the results is performed. The findings show that the participants in the EXG have asked fewer LOQs in their post-test due to the explicit instruction and intense restructuring training received in the treatment sessions, which is statistically significant $(t(13)=3.67, p<.05)$. They have also asked more HOQs when their mean score in the pre-test is compared with that in the post-test, which is again statistically significant $(t(13)=-2.85, p<.05)$. The significance indicates that participants have developed awareness of the six levels of Qs by strategically switching from asking the levels of Qs they know better to asking the levels of Qs they need more training. Of course, these findings should not be interpreted as reducing LOQs and increasing HOQs are the aim of this training because LOQs do create pedagogical effectiveness depending on purposes. Instead, the action of switching emphasizes participants' developed awareness of the varying levels of Qs, which enables them to target at what they lack to improve. However, questions may be raised about how to interpret the non-significant result obtained from comparing the total number of Qs in the two tests. It seems legitimate to assume that the total number of Qs asked in either test could not be directly interpreted as levels of Qs nor divergence of Qs.

When a deeper analysis of the levels of Qs is performed to see the extent of awareness, it is interesting to find Understand Qs, among the three levels of LOQs (Remember, Understand, and Apply) takes the majority in the pre-test for the EXG, which is also true with the CG. Among the EXG's Understand Qs are the cognitive processes of Explaining and Exemplifying Qs that rank first and second in the aligned seven cognitive processes (See Appendix B) while Inferring and Summarizing rank the last on the list. In their post-test, Analysis Qs seem to dominate participants' attention when they compose HOQs. Within the three cognitive processes (Differentiating, Organizing, and Attributing) of that level, Attributing clearly ranks at the top. These findings could be interpreted as participants are better at asking Understand Qs before training, yet after training tend to ask more Analysis Qs. The findings further suggest pedagogical implications as they confirm the argument that Qs people ask release their "incompleteness" and "lacks" (Fiengo, 2007, p. 3). Certainly, caution must be taken when interpreting further because the type of content used for generating Qs might also contribute to the cognitive processes that need to be selected. However, the findings clearly indicate the potential of identifying particular questioning levels and processes for which participants lack awareness or have not completely mastered, and which are more teachable through training or are more challenging to learn. For example, Creation Qs seem to be the hardest level to be trained because the intense restructuring training has not sufficiently helped them produce a noticeable number of Creation Qs. The processes of summarizing or inferring for understanding and differentiating or organizing for analyzing as they rank the last may be worth further attention.

The 11-item post-questionnaire conducted in the $9^{\text {th }}$ week elicits participants' immediate reflection on the awareness that the sessions have raised. The descriptive results shown in Table 4 indicate that the explicit training on questioning strategy has made participants aware of levels of Qs as well as DQs. Those percentages, from 79\% to 93\%, associated with the awareness aspects such as levels of Qs, DQs, and positive experience, significantly indicate that explicit questioning strategy training has drawn over $79 \%$ participants' attention to questioning strategies. This indication, is first confirmed by participants' consistent responses to Q5 about any aspects of the practices TRULY drawing their attention and is further verified by the negative response to Q6 about any aspects of the practices NOT raising their awareness. The $100 \%$ confirmation of the first-time questioning strategy training indicates participants' lack of training and assumes the full extent of awareness of this type of instruction. Though the participants have expressed observable challenges when applying the Q-Q Game in practice, over half (59\%) of them have reported awareness of the tool's potential in creating new opportunities to ask DQs. The written examples provided to illustrate various perspectives of asking Qs also indicate participants' awareness of the divergence created by the tool.

An integral component of practices focused on stating Qs clearly, accurately, and meaningfully further reflects the operationalization of the social-cognitive approach to questioning strategy learning. The repeated peer interaction and revising procedures applied in all treatments utilizing the same set of Qs asked by participants in the pre-test and the QQ Game have fully illustrated what "contextualized" (Ortega, 2009; Oxford, 2011, 2017), "restructured" (DeKeyser, 1997, 2007), and "noticed" (Schmidt,1990, 1992) social and cognitive features mean in the research. Table 4 shows the average length per Q asked is shortened from 21.4 words in the pre-test to 17 words in the post-test, which implies participants' awareness of conciseness of asking Qs in the post-test. This finding might be questioned as whether the shorter the question is better. Actually, that is true with one of the criteria of Socratic Qs emphasizing conciseness of a question (Nappi, 2017). Scaffolded by the designed practices to revise Qs based on given criteria, the participants have deeply approached Qs and revised each other's Qs multiple times. The emergence of more grammatical, meaningful, and concise Qs in the post-test reflects the effect of peer-editing and peer-questioning with contextualized Qs. The Qs asked in their question journals provide additional evidence that participants have purposefully tried to apply the strategies in new situations. These findings corroborate the result of productive use of questioning forms is developmentally effective and optimized (McDonough \& Mackey, 2006, 2008). They further expand the corroboration that the productivity could be particularly more effective for certain levels of Qs such as asking Analysis Qs and reducing Understand Qs, but not all levels of Qs, like Creation Qs, can be trained at the same rate.

When comparing the findings from the EXG with the CG, no statistical significance was found, which might be due to the imbalanced ( $N=14$ vs. 7 ) or limited number of participants; therefore, the effect size is not computed through 
quantitative analysis. However, the nature of the complexity of the problem might find evidence from the qualitative analysis, which could be meaningful and pedagogically directive. The CG asked an overwhelming number of Understand Qs in the post-test when they are compared with the significant decrease of the same level of Qs in the EXG. Also the high number of Yes/No Qs asked by the CG might indicate their "lack" and "incompleteness" (Fiengo, 2007) and justify the high percentage of Understand Qs. Alternatively, they have attempted to understand the content, but they are limited in strategies to probe other higher levels of questioning. In contrast, the EXG has showed greater variety and significantly asked more HOQs after the training.

\section{LIMITATIONS AND FUTURE RESEARCH}

Although such a complex construct as questioning strategy is difficult to operationalize, this study has attempted the development through carefully designing the interventional practices aligned to the Revised Taxonomy. However, a bigger sample of participants in both groups would allow the study to be more replicable, though the qualitative data have attempted to reduce this limitation. L1 language differences could be investigated to see how an L1 contributes to asking questions. A delayed post-test could be used to determine the long-term effect. Finally, it would be interesting to investigate why it is so hard to ask Creation Qs.

\section{CONCLUSION}

The overall purpose of this study is to examine the extent to which explicit instruction in questioning strategies could develop learner teachers' awareness of levels of Qs and DQs. The study finds that the explicit instruction has significantly developed L2 learner teachers' awareness of asking varying levels of Qs based on the Revised Taxonomy as well as asking Qs from different perspectives. The statistical analyses show that they have significantly asked more HOQs and reduced LOQs due to the productively restructuring practices. In their HOQs, Analysis Qs become the most frequently asked while in the LOQs, Understand Qs become the most frequently reduced. These findings do not mean increasing HOQs and reducing LOQs are the ultimate goals of this study. Instead, they indicate that the learner teachers are made aware of the levels of Qs and are empowered to tackle questioning strategies they need more. A comparison made with the CG is insignificant regarding the differences in asking LOQs vs. HOQs, possibly due to the imbalanced number of participants, but the finding of a majority of Yes/No Qs in the CG compared with that of the clearly lowered percentage in the EXG strongly indicates the former has limited awareness of other types of Qs. The qualitative findings from the post-questionnaire indicate participants' clear awareness of levels of Qs and DQs. The high percentages of confirmation of learning and awareness, including first time experience of the questioning strategy training and the Q-Q Game, support the quantitative significance. This support further implies that productive use of questioning forms through contextualized restructuring activities from a social-cognitive perspective facilitates identifying particular questioning strengths and weaknesses in the cognitive domain. The results indicate potential pedagogical paths for L2 learner teachers from non-Socratic educational contexts to catch up on the missed questioning education. These paths can be explored through a level-by-level and process-by-process questioning training approach supported by the effective Q-Q Game that scaffolds L2 learner teachers to question content divergently, interactively, and productively.

\section{APPENDiX A. POST-QUESTIONNAIRE}

Is your experience with the questioning skills practice...?

Very Positive Positive Neutral Negative Not Sure

To what extent have these sessions raised your awareness of asking good questions?

Fullest Extent Noticeable Extent Some Extent Little Extent Not Sure

To what extent have the practices made you think about asking different questions in other situations over the past few weeks?

Fullest Extent Noticeable Extent Some Extent Little Extent Not Sure

Is there anything in these practices that you have never thought about before?

What are the aspects of the practices that have TRULY drawn your attention to ask good questions?

What are the aspects of the practices that have NOT raised your awareness of asking good questions?

Have you ever tried to use some of the techniques you learned in the practices in other classes?

What things have you learned from these training sessions if any?

Can you name any strategies/skills that you might use in your future?

Can you define what questioning skills mean to you up to now?

What is your overall evaluation of these practice sessions? 
Appendix B. 6 Levels of Questions \& 19 Aligned Cognitive Processes

\begin{tabular}{|c|c|c|c|c|c|c|}
\hline \multicolumn{7}{|c|}{6 Levels of Questions } \\
\hline \multirow{9}{*}{19 Processes } & 1 & 2 & 3 & 4 & 5 & 6 \\
\hline & Remember & Understand & Apply & Analyze & Evaluate & Create \\
\hline & Recognizing & Interpreting & Executing & Differentiating & Checking & Generating \\
\hline & Recalling & Exemplifying & Implementing & Organizing & Critiquing & Planning \\
\hline & & Classifying & & Attributing & & Producing \\
\hline & & Summarizing & & & & \\
\hline & & Inferring & & & & \\
\hline & & Comparing & & & & \\
\hline & & Explaining & & & & \\
\hline
\end{tabular}

\section{APPENDix C. EXAMPLe ThINKING SKILls HANDOUT}

\section{Level: Application Question}

Defining: Focusing on solving problems and using it in news situations. You are able to select, transfer, use information and generalizations to complete a task through taking what you know and applying it to new situations

Thinking skills (aligned processes)

Problem-solving, exampling, classifying, selecting, transferring, applying, hypothesizing, relating

Questioning functions/structures:

Whom would you choose? What would happen if ...? If... how can ...? What examples ...? What would you ...?

\section{ApPendix D. EXAmple Practices ScafFolded By the Q-Q Game}

Source Question (Q): Do you like English?

Answer (A): What behaviors do you count as like English?

Q: Is reading English novels a sign of loving English?

A: How often do you read novels?

Q: Why do you think reading novels frequently is so important to show my interest?

A: Would you be more engaged if you read a novel?

\section{ACKNOWLEDGEMENTS}

I would like to sincerely thank the study participants, whose dedicated participation made this research possible.

\section{REFERENCES}

[1] Anderson, L., \& Krathwohl, D. E. (2001). A Taxonomy for learning, teaching, and assessing: A revision of Bloom's taxonomy of educational objectives [Abridged]. New York: Addison Wesley Longman.

[2] Bauer, L., \& Trudgill, P. (1998). Language myths. New York: Penguin Putnam.

[3] Blank, S. S., \& Covington, M. (1965). Including children to ask questions in solving problems. Journal of Educational Research, 59, 21-27.

[4] Brock, C. A. (1986). The effects of referential questions on ESL classroom discourse. TESOL Quarterly, $20,47-5$.

[5] Brown, D. \& Lee, H. (2015). Teaching by principles: An interactive approach to language pedagogy ( $4^{\text {th }}$ ed.). NY: Pearson.

[6] Canale, M. , \& Swain, M. (1980). Theoretical bases of communicative approaches to second language teaching and testing. Applied Linguistics, 1, 1-47. DOI: http://dx.doi.org/10.1093/applin/I.1.1.

[7] Celce-Murcia, M., Briton, D. M. \& Snow, M. A. (Ed.). (2014). Teaching English as a second or foreign language (4 ${ }^{\text {th }}$ ed.). Boston: National Geographic.

[8] Cohen, A. D. (2010). Focus on the language learner styles, strategies and motivation in Norbert Schmitt (ed.) An introduction to applied linguistics $\left(2^{\text {nd }}\right.$ ed.), pp. 161-178. London: Hodder Education.

[9] Cohen, A. D. \& Macaro, E. (2007). Language learner strategies. New York: Oxford University Press.

[10] Cotton, K. (1989). Classroom questioning. School Improvement Research Series. Northwest Regional Educational Laboratory.

[11] Cronk, B. C. (2018). How to use SPSS®: A step-by step guide to analysis and interpretation (10 ${ }^{\text {th }}$ ed.). New York, NY: Routledge.

[12] Davoudi, M. \& Sadeghi, N. A. (2015). A systematic review of research on questioning as a high-level cognitive strategy. English Language Teaching, 8(10), 76-90. DOI:10.5539/elt.v8n10p76.

[13] DeKeyser, R. (1997). Beyond explicit rule learning: Automatizing second language morphosyntax. Studies in Second Language Acquisition. 19, 159-221. DOI: http://dx.doi.org/10.1017/S0272263197002040.

[14] DeKeyser, R. (Ed.). (2007). Practice in a second language: Perspectives from applied linguistics and cognitive psychology. New York, NY: Cambridge University Press.

[15] Dös, B.; Bay, E.; Aslansoy, C.; Tiryaki, B.; Çetin, N.; Duman, C. (2016). An analysis of teachers' questioning strategies Educational Research and Reviews, 11 (22), 2065-2078. DOI: https://doi.org/10.5897/ERR2016.3014.

[16] Ellis, N. C. (2002). Frequency effects in language acquisition: A review with implications for theories of implicit and explicit language acquisition. Studies in Second Language Acquisition. 24, 143-188. DOI: https://doi.org/10.1017/S0272263102002024.

[17] Farrell, T. S. C. \& Mom, V. (2015). Exploring teacher questions through reflective practice, Reflective Practice, 16:6, 849-865. 
[18] Freed, A., \& Ehrlich, S. (2010). Why do you ask? The function of questions in institutional discourse. New York: Oxford University Press.

[19] Fiengo, R. (2007). Asking questions: Using meaningful structures to imply ignorance. New York: Oxford University Press.

[20] Jackson, J. (2002). Reticence in second language case discussions: Anxiety and aspirations. System, 30(1), 65-84. DOI: http://dx.doi.org/10.1016/S0346-251X(01)00051-3.

[21] Koshik, I. (2010). Questions that convey information in teacher-student conferences. In Alice F. Freed \& Susan Ehrlich (Eds.). "Why do you ask?" The function of questions in institutional discourse (pp. 159-186). New York: Oxford University Press.

[22] Larsen-Freeman, D. (2018). Looking ahead: Future directions in, and future research into, second language acquisition. Foreign Language Annals. 51, 55-72.

[23] Lindfors, J. W. (1999). Children's inquiry: Using language to make sense of the world. New York: Teachers College Press.

[24] Mackey, A. (1999). Input, interaction, and second language development: An empirical study of question formation in ESL. Studies in Second Language Acquisition, 21, 557-587. DOI: http://dx.doi.org/10.1017/S0272263199004027.

[25] McCormick, D. E., \& Donato, R. (2000). Teacher questions as scaffolded assistance in an ESL classroom. In J. K. Hall \& L.Verplaetse (Eds.), Second and Foreign Language Learning through Classroom Interaction (pp. 183-201).Mahwah, N.J: Lawrence Erlbaum.

[26] McDonough, K., \& Mackey, A. (2006). Responses to recasts: Repetitions, primed production, and linguistic development. Language Learning, 56(4), 693-720. DOI: https://doi.org/10.1111/j.1467-9922.2006.00393.x.

[27] McDonough, K., \& Mackey, A. (2008). Syntactic priming and ESL question development. Studies in Second Language Acquisition, 30, 31-47. DOI: http://dx.doi.org/10.1017/S0272263108080029.

[28] McKenzie, J. (2005). Learning to question to wonder to learning. Bellingham, Washington: FNO Press.

[29] Morgan, N., \& Saxton, J. (1991). Asking better questions: Models, techniques and classroom activities for engaging students in learning. Markham, Ontario: Pembroke Publishers.

[30] Nappi, J. (2017). The importance of questioning in developing critical thinking skills. The Delta Kappa Gamma Bulletin: International Journal for Professional Educators. 84(1), 30-41.

[31] Nunan, D. (1990). The questions teachers ask. JALT Journal, 12(2), 187-202.

[32] Nelson, K., \& Earl, N. (1973). Information search by pre-school children: induced use of categories and category hierarchies. Child Development, 44, pp. 682-685.

[33] O’Malley, J. M. \& Chamot, A. U. (1990). Learning strategies in second language acquisition, Cambridge, New York: Cambridge University Press. DOI: https://doi.org/10.1017/S0267190500002452.

[34] Oxford, R. L. (1990). Language learning strategies: What every teacher should know. New York: Newbury House/Harper Collins.

[35] Oxford, R. L. (2011). Teaching and researching language learning strategies. Harlow, UK: Pearson.

[36] Oxford, R. L. (2017). Teaching and researching language learning strategies self-regulation in context ( $2^{\text {nd }}$ ed.). NY: Routledge.

[37] Sarangi, S. (2010). The spatial and temporal dimensions of reflective questions in genetic counseling. In Alice F. Freed \& Susan Ehrlich (Eds.). "Why do you ask?” The function of questions in institutional discourse (pp. 235-255). New York: Oxford University Press.

[38] Schmidt, R. W. (1990). The role of consciousness in second language learning. Applied Linguistics, 11, 129 58. DOI: https://doi.org/10.1093/applin/11.2.129.

[39] Schmidt, R. W. (1992). Awareness and second language acquisition. Annual Review of Applied Linguistics, 13, $206-26$. http://dx.doi.org/10.1017/S0267190500002476.

[40] Sun, Z. (2012). An empirical study on new teacher-student relationship and questioning strategies in ESL Classroom, English Language Teaching, 5 (7), 175-183. DOI: http://dx.doi.org/10.5539/elt.v5n7p175.

[41] Toni, A. \& Parse, F. (2013). The status of teacher's questions and students' responses: The case of an EFL class. 4(3), Journal of Language Teaching and Research, 564-569. doi:10.4304/j1tr.4.3.564-569.

[42] Wiederhold, W. C. (2007). Question Matrix: Creative learning and higher order thinking in consultation with Spenser Kagan (illustrated ed.). Heatherton, Vic. Au. : Hawker Brownlow Education.

[43] Wu, K. (1993). Classroom interaction and teacher questions revisited. RELC Journal, 24(2), 49-68. DOI: http://dx.doi.org/10.1177/003368829302400203.

[44] Xia. S. (2009). Are they ready to participate? East Asian students' acquisition of verbal participation in American classrooms. Issues in Applied Linguistics, 17 (2), 137-157.

[45] Yaqubi, B., \& Mozaffari, F. (2011). EFL teacher questions to scaffold learning process: A conversation analytic study. The Journal of Applied Linguistics, 4(1), 228-259.

[46] Zimmerman, B. J., \& Pike, E. O. (1972). Effects of modeling and reinforcement on the acquisition and generalization of question-asking behavior. Child Development, 43, 892-907. DOI: 10.2307/1127640.

Saihua Xia is an Associate Professor in the TESOL MA program of Murray State University, USA. She teaches graduate and undergraduate TESOL courses. Her research interests include Teacher Education, SLA, Intercultural Pragmatics, and Virtual Learning. She has published in various peer-reviewed journals. She is very active in providing professional service to her State/Regional TESOL organizations and the TESOL International Association. 